\title{
Study on English Translation of China's Tea-Business Publicity Materials from the Perspective of Skopos Theory
}

\author{
Lingyun Chu \\ School of Foreign Languages \\ Harbin University of Commerce \\ Harbin, China
}

\begin{abstract}
With the development of global economy, an increasing number of tea companies manage to export their products in the way of brand export. Qualified translation of publicity materials will help the target customers know well about the company, purchase their products and therefore increase their profits. The paper aims to summarize the features of publicity materials at lexical and textural levels. Based on the summary, three possible translation methods are proposed to provide some references and guidance for the English translation of Chinese Tea-business publicity materials.
\end{abstract}

Keywords - tea industry; Chinese publicity materials; Skopos theory; English translation

\section{INTRODUCTION}

China's is the birthplace of tea and its production and exports are in front rank of the world. More and more foreign customers have had a taste in sipping tea in their leisure time. In current years, many a tea company has already enjoyed good reputation at home and abroad. However, many other companies are in urgent needs to open overseas market by building up their own brands.

The publicity material is mainly about the products and operation of the company, through which customers may have a chance to know about the company and their products. Therefore it plays a considerably significant role in opening or expanding foreign markets. As we all know, publicity materials are mainly for publicizing the company with obvious purposes of attracting consumers and improving sales. It is feasible to investigate the differences and similarities of English and Chinese publicity materials and then put forward the corresponding translation strategies under the guidance of Skopos theory developed by German Functionalist School.

Sponsors: 2016 Project of Teaching Reform and Teaching Research in Harbin University of Commerce "Study of Flipped Classroom in Business English Translation Course” (HSDJY08(Z)); Education and Scientific Planning of Heilongjiang Province "Study of Teaching Mode of Business English Translation” (GJD1215018); 2016 Project of Academic Team Building in Harbin University of Harbin Commerce " Research on Translation of Publicity Materials from the Perspective of Medio translatology” (2016TD017)

\section{INTRODUCTION TO SKOPOS THEORY}

\section{A. Overview of Skopos Theory}

Prior to the 1970's, translation practices and translation theories were mainly analyzed and explained from the linguistic perspectives. The origin of almost every translation theory at that time could be traced to some linguistic school. Thus it is safe to conclude that translation studies were subordinate to linguistic studies

In the 1970s, Hans Vermeer started the Skopos theory and stated his position as follows: Any form of translational action, including translation itself, may be conceived as an action, as the name implies. Any action has an aim, a purpose ... The word skopos, then, is a technical term for the aim or purpose of a translation (Nord, 2001: 12). Translation is a transform process. Any translation practice is with a certain objective or aim and produce a new result, a new context or issue. In the process of translation, the translator should give priority to the client's purpose or the communicating function of translation texts. By doing so, the theory has demoted the influence of linguistics exerted to the translation studies. "Natural equivalence" is never the principle of examining translation quality as long as the translations fulfill the clients' communication needs.

\section{B. Three Rules of Skopos Theory}

According to Skopos theory, translators should abide by three rules: the skopos rule, the coherence rule and the fidelity rule. Fidelity rule is subordinate to coherence rule, and the two rules are both subordinate to the Skopos rule which is counted as the core of the theory. We can say that the three rules of Skopos theory are of overreaching importance to serve as a bridge and bond between source text and target text. Therefore, apply Skopos theory to the research of subtitle translation is appropriate and feasible. The three basic rules will be briefly described one by one in the following sections.

- Skopos Rule: Vermeer believed that human activity is determined by the end or the skopos and so does the translation activities which have followed one or more purposes. In other words, in the process of translation, the skopos or the function of the target 
text decides what kind of translation strategies that the translator to use. The skopos rule pointed out that the translation should achieve the effect by the way that the target audience expected in the target language and cultural contexts. The skopos of translation is further divided into three categories, firstly, the basic purpose of the translator; secondly, communicative purposes of the target text; thirdly, specific translation strategies or means to achieve the purpose.

- Coherence Rule: Coherence rule which emphasized on the target text that translated by the translator should conform to the culture of the target receivers (Reiss and Vermeer, 1984:118). The coherence rule requires that the translation of the target text should be understandable and acceptable as much as possible which can finally realize the intertextual coherence and should conform to the communicative situation of the target language recipient and ensure the recipient understand the target language.

- Fidelity Rule: The fidelity rule is the last principle except the skopos rule and the coherence rule the author have introduced. Compared with the coherent rule or the intratextual coherence, the fidelity rule is also called as the intertextual coherence. The fidelity rule expects to establish a particular relationship between the target text and the source text which in a sense similar to the "faithful" of other translation theories. However, the meaning of the fidelity rule in the skopos theory has its own special sense which is much different to the concept of faithful principle. The fidelity is built on the interpretation of the source text and translation purposes (Nord, 1997:32). In other words, the extent of the fidelity will change with the change of purpose, which is different to the "faithful" of other conventional translation theories.

\section{StYlistic AND CUltural Features OF PUBlicity MATERIALS}

\section{A. Stylistic Features}

Chinese expressions in publicity materials are flexible and subtle. Chinese prefer to approach a subject without coming straight to the point or "beat about the bush" and render the subject detailed. By contrast, the westerners come straight to the point or "cut the cackle". The Chinese publicity material puts stress on logical organization of the text and put the major information and subject at the end of the text.

Under the influence of Chinese thinking habit, the flow of Chinese publicity material tends to render complicated expressions and make plenty of quotations, which lead naturally to the subject. But the English texts come directly to the point.

\section{Example 1: English publicity material}

The jasmine plant, (there are about 200 sub-varieties) grow in mainly tropical regions of the world and China is an absolutely ideal location for jasmine to grow and it matches fabulously with green tea which also originates from China.

Example 2: Chinese publicity material

花茶是中国特种茶之一, 原产地福建。福建莱莉花产量 大, 品质优, 茶以花名, 花以茶胜。经七百多年历史, 至今驰 名中外。其工艺只要精选高山茶园的烘青绿, 配以上等的荣莉 花, 采用传统的工艺和现代技术空质而成。使茶味花香融为一 体，形成风格独特的 “福建味”。

Analysis: The Chinese publicity material starts with the statement of the large volume of jasmine and its good quality and then shift to the main point - the description of the ways to make jasmine tea. In the description of manufacturing methods, “精选” (selective) and “等” (delicate) are adopted to render it complicated to show the good quality of jasmine. On the contrary, the English publicity material directs to the point - the description of the raw material-jasmine and green tea and then give the brief and general explanation.

In addition, the Chinese writers pay more attention to colorful wording, consonant lyrics, and strong emotion surging but less attention to the tight organization of the text, which is demonstrated by the loose link between sentences and scarce use of connectives. The coherence of the Chinese publicity materials is mainly achieved by sentence meaning and the sequence of occurrences. Instead, the English language is famous for its tight organization and logical flow of the texts. The English writers are carefully about the grammatically correct sentences and clear-cut sentence structures. Logical predication is satisfied by a variety of connectives.

\section{B. Cultural Features}

In China, tea culture enjoys a long history against Buddhist, Daoism and Confucianism backgrounds. Therefore, most of the Chinese publicity materials are inclined to list long history of their businesses to show their peculiarity and authority.

The English materials take interest in the factual manufacturing states and concentrate on their qualification and certificates. The ultimate goal is to publicize the good quality of tea itself instead of authoritative comments and remarks.

\section{Translation StRategies From the PERSPECTIVE OF SKOPOS THEORY}

\section{A. Omission}

From the above statement of features, the Chinese publicity materials are featured with set phrases and parallel sentences. The materials tend to list rewards and awards, the celebrities' words and ideas with Chinese characteristics to provide evidence to show the comprehensive strength of the companies. However, the target consumers are not familiar with the names of awards and the celebrities' words. Moreover, it is also hard for the customers to understand the ideas and thoughts with Chinese Characteristics. Hence, taking customers' reaction into consideration, the translators often omit to translate them. 


\section{B. Amplification}

The translation of tea names is also involved in the Chinese publicity materials. In China's broad realm, different climate and different soil have great impact on tea qualities. For example, Oolong prefers mountains. Therefore, there are different kinds of tea in different areas. The tea companies develop different skills to make tea in order to build up their reputations.

\section{Adaption}

Due to the difference in mindset of the Chinese and the westerners, the Chinese publicity materials favor parallelism in sentence structure to achieve natural flow. The logical link is between words and the theme is put at the very end of the text. The westerners prefer to come straight to the point and usually the theme is put at the very beginning of the text.

\section{CONCLUSION}

With the advancement of global economy, tea companies in China have a lot of chances to gain profits from other countries. Qualified and good translations of publicity materials are keys to sales promotion overseas.

\section{REFERENCES}

[1] Nord. Christiane, Translating as a purposeful activity: functionalist approaches explained. Manchester: St. Jerome Publishing, 1994.

[2] Nord. Christiane, A Functional Typology of Translation and Skopos in Translation. Amsterdam \& Philadelphia Benjamin, 1997.

[3] Reiss. K, and Vermeer. H. J., Groundwork for a General Theory of Translation. Tubingen: Niemeyer, 1984.

[4] Liu Jing, "Translation of Tea Names from the Perspective of Skopos Theory: Problems and Strategies," Journal of Language and Literature, vol. 4, pp. 51-54, 2014.

[5] Zhao Ping, and Tan Zhengxin, "A Study of the Features of Translation for China's Global CommunicationReflecting in the English Version of Yunnan Pu-erh Tea," Journal of Yunnan Agricultural University, vol. 5, pp. 113-117, 2011. 